\title{
Article
}

\section{The making of expert performers at Cirque du Soleil and the National Circus School: A performance enhancement outlook}

Filho, Edson, Aubertin, Patrice and Petiot, Bernard

Available at http://clok.uclan.ac.uk/14191/

Filho, Edson ORCID: 0000-0002-8548-4651, Aubertin, Patrice and Petiot, Bernard (2016) The making of expert performers at Cirque du Soleil and the National Circus School: A performance enhancement outlook. Journal of Sport Psychology in Action, 7 (2). pp. 68-79. ISSN 2152-0704

It is advisable to refer to the publisher's version if you intend to cite from the work. http://dx.doi.org/10.1080/21520704.2016.1138266

For more information about UCLan's research in this area go to http://www.uclan.ac.uk/researchgroups/ and search for <name of research Group>.

For information about Research generally at UCLan please go to http://www.uclan.ac.uk/research/

All outputs in CLoK are protected by Intellectual Property Rights law, including Copyright law. Copyright, IPR and Moral Rights for the works on this site are retained by the individual authors and/or other copyright owners. Terms and conditions for use of this material are defined in the policies page. 
EXPERTISE AND PERFORMANCE PSYCHOLOGY IN CIRCUS

2 Paper in Press at the Journal of Sport Psychology in Action

3 DOI: $10.1080 / 21520704.2016 .1138266$

4 This version may slightly differ from the published version by the copyright owner.

5

6

7

8

The Making of Expert Performers at Cirque du Soleil and the National Circus School:

9

10

11

12

13

\section{A Performance Enhancement Outlook}

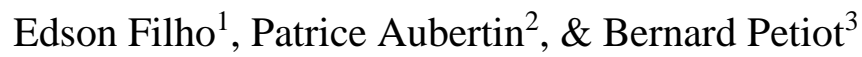

${ }^{1}$ University of Central Lancashire, School of Psychology (UK)

${ }^{2}$ National Circus School (CA)

${ }^{3}$ Cirque du Soleil Headquarters (CA)

Corresponding Author:

Edson Filho

University of Central Lancashire

School of Psychology

Darwin Building, DB114

Preston

Lancashire

PR1 2HE

efilho@uclan.ac.uk 
EXPERTISE AND PERFORMANCE PSYCHOLOGY IN CIRCUS

31

Abstract

33 In this paper, an applied analysis of the psychological processes and skills necessary for

34 performance artists to excel in contemporary circus is presented. This analysis is based on

35 applied experience at Cirque du Soleil and the National Circus School, leading contemporary

36 circus programs in the world. The importance of learning the rules of the circus domain,

37 transferring motor skills to the circus environment, and developing an artistic identity and

38 mindful mind-set are discussed. Furthermore, general and discipline-specific performance

39 pressures are identified and discussed in light of current performance enhancement

40 techniques.

41 Keywords: contemporary circus, expert performance, mental skills. 
EXPERTISE AND PERFORMANCE PSYCHOLOGY IN CIRCUS

\section{The making of expert performers at Cirque du Soleil and the National Circus School:}

\section{A performance enhancement outlook}

The contemporary circus movement, which emerged in the 1980s, differs from the longstanding traditional circus milieu (for a review see Albrecht, 2006). Most noticeably, contemporary circus shows are animal-free and narrative-driven, wherein every act is interconnected around a central theme or storyline (Leroux, 2014). The emphasis is on human performance in its broader sense, as performing artists across disciplines (e.g., acrobats, actors, clowns, dancers, jugglers, and singers) are invited on stage to "tell a story". In this context, the purpose herein is to offer an applied analysis of the psychological processes and skills necessary for performance artists to excel in contemporary circus. This analysis was based on a series of visits to one of the leading circus schools in the world (National Circus School, thereafter "NCS"), and the premier contemporary circus company in the world (Cirque du Soleil, thereafter "CDS"). I start by describing the background and methodological approach that substantiate the insights presented herein. Next, I discuss how expert performance in circus requires both acrobatic and artistic skills. I then elaborate on the psychological demands proper to circus acts. I conclude by describing avenues for future applied work in the circus domain. My analysis is followed by independent replies from directors at NCS and CDS.

\section{Background and methodological approach}

Although this paper reflects my experiences, the ideas expressed herein were methodologically triangulated in an attempt to increase trustworthiness. The subsequent report was based on the triangulation of focus groups, unstructured interviews, observations of shows and practices, and the maintenance of a reflexive journal. These established qualitative methods were inductively juxtaposed (see Braun \& Clarke, 2006) and are 
EXPERTISE AND PERFORMANCE PSYCHOLOGY IN CIRCUS

graphically represented to offer an applied view of the role of performance psychology in the development and preparation of performing artists in circus.

The focus groups consisted of round table discussions on expertise development in circus and involved head coaches and executive leaders at NCS and CDS. The unstructured interviews involved informal conversations with coaches and performers, occurred during practices or prior to a show, and centred on topics related to coaching and performance psychology. The interviews were not recorded as NCS and CDS leaders asked for a more informal approach to avoid disrupting the daily routine of the coaches and performers. The key points of each interview were written down and subsequently summarized in a reflexive journal. Observations of five different shows, from both an audience and back-stage perspective, were also recorded in a reflexive journal. Observed shows included L'abri and La matrice de Morphée produced by NCS, and Amaluna, Kurios, and KA by CDS. Two independent replies from executive leaders at NCS and CDS are presented at the conclusion of this commentary, similar to the notion of "external judges" in qualitative inquiry (see Patton, 2002). The overarching idea was to share my applied experience at two leading contemporary circus programs, while striving to produce a trustworthy and transferrable report that may aid practitioners working with performing artists.

\section{Cross-domain expertise: From acrobats to circus "acro-artists"}

Most circus performers engage in some sort of acrobatics, broadly defined as "a spectacular, showy, or startling performance or demonstration involving great agility or complexity" (Merriam-Webster Dictionary, 2015). Although visually attractive, gymnastic moves and exhibitions of agility are not sufficient ingredients for a successful career in contemporary circus. Executive leaders, coaches, and performers at both NCS and CDS affirmed that one needs to become an "acro-artist" to attain high levels of performance in circus. An acro-artist, as the name implies, is someone who successfully integrates acrobatic 
EXPERTISE AND PERFORMANCE PSYCHOLOGY IN CIRCUS

and artistic skills (see Ménard \& Hallé, 2014). The process of becoming an acro-artist, and ultimately an expert circus performer, involves adapting to the circus context and developing “on stage" performance skills (Figure 1).

\section{Contextual adaptation: Learning the "Rules of the domain"}

Circus is a unique domain that carries its own requirements for expert performance and creativity development. Accordingly, aspiring circus performers who migrate from other disciplines must learn the unwritten rules of the circus arts. Csikszentmihalyi (1996) has contended that expert performance and creativity require mastering the "rules of the domain", which include the techniques, behaviours and symbols needed to succeed in a given performance context. During the interviews, several coaches commented on the importance that performers, especially those from a sport background, understand that circus is a multitask enterprise. In fact, circus acts resemble interactive sports, wherein intra-team coordination is central to performance (Filho \& Tenenbaum, 2012). As such, "all-star athletes", particularly those coming from individual sports and accustomed to performing solo acts, need to develop domain-specific shared mental models, namely communal schemas about the tasks and strategies needed to achieve spatiotemporal coordination in interactive group tasks (Mohammed, Ferzandi, \& Hamilton, 2010).

$$
\text { In addition to developing shared mental models, aspiring circus performers need to }
$$

become acculturated with what the coaches refer to as the "big top (circus) community". The circus community is international in nature and performers need to develop multi- and crosscultural sensitivity as well as overcome language barriers. In this respect, the "big top community" resembles the sports world, wherein international athletes have been found to differ in their perceived performance expectations (Filho, Gershgoren, Basevitch, \& Tenenbaum, 2014) and cultural behaviours compared to local players (Schinke, Gauthier, Dubuc, \& Crowder, 2007). The performers must also recognize that they are professionals 
EXPERTISE AND PERFORMANCE PSYCHOLOGY IN CIRCUS

embarking on a potentially life-long career. A career in the circus, according to one artistic coach, "is not an Olympic cycle. It is a 15 to 20 year long career." As such, similar to professional athletes, circus artists must balance stress and recovery in order to prevent overreaching and, ultimately, overtraining and burnout (Kellmann, 2010). After learning these basic rules of the domain, performers develop domain-specific skills to ensure a successful and lengthy career.

\section{Skill development: "Learning to be on stage"}

Circus is ultimately a conversation with the audience. Therefore, individuals from different backgrounds need to learn how to effectively interact and perform on stage. Senior casting and performance coaches at CDS described how this learning process, along with the contextual adaptation process described above, is facilitated by "Organizational Excellence Teams" (Figure 1). These teams consist of coaches with various specializations, health professionals (e.g., nutritionists, doctors and physiotherapists), and performance enhancement specialists. These professionals serve as role models for the aspiring circus artists who, by observing and conversing with more experienced professionals (i.e., vicarious experiences and verbal persuasion; see Bandura, 1997; Feltz, Short, \& Sullivan, 2008), develop increased efficacy beliefs in their ability as circus artists. Moreover, the practice of "Organizational Excellence" is congruent with the notion of transactive memory systems in organizational psychology (see Hollingshead \& Brandon, 2004), wherein individuals learn how to access the information they need within the institution they work in order to develop domain-specific knowledge and achieve high levels of performance. In contemporary circus, the path to expertise also includes the development of technical and emotional skills.

Development of technical skills. Individuals entering a career in circus need to adapt their skills to the new environment. In motor learning theory this process is referred to as transfer of skills, and consists of (a) using previously mastered skills as the basis to learn new 
EXPERTISE AND PERFORMANCE PSYCHOLOGY IN CIRCUS

skills or, (b) applying a skill learned in one context (e.g., gymnastics) to another context (Wang \& Chen, 2014). At NCS and CDS, transfer of skills is maximized through training regimes based on the notion of "open improvisation". Specifically, training sessions designed for a given circus act or show storyline (e.g., time, action, and space) are conducted, where the acro-artist apprentices learn to transfer their skills from other domains to the circus environment. For example, a gymnast will not be completing a vault routine as in traditional gymnastics, but rather will be using those skills to jump over and interact with myriad objects during a circus act.

Development of emotional skills. Different emotional skills have been linked to peak performance in the circus arts (Ménard \& Hallé, 2014; Nordin-Bates, 2012). During my experience at NCS and CDS, two emotional skills were identified as paramount by the artistic and acrobatic coaches. Performers need to develop a self-concept as an artist, or their artistic identity. This process involves learning how to act by expressing emotions through verbal and non-verbal communication. At NCS and CDS, the circus apprentices engage in a series of acting exercises where they play different roles and explore various scenarios in order to determine the emotions and behaviours that work best for them on stage. This is akin to how athletes practice in order to identify the cognitive-affective-behavioural states that will enable them to enter their zone of optimal performance (see Hanin, 2007; Tenenbaum, Basevitch, Gershgoren, \& Filho, 2013). According to self-complexity theory, novel self-concepts can be developed as people explore new personal and professional areas (Rafaeli-Mor \& Steinberg, 2002). Once an individual has "opened up to be an artist", as one coached pointed out, it is important that s/he develops a mindful mind-set in order to connect with the audience. Mindfulness is a multi-layered meta-cognitive process that has affective-cognitivebehavioural implications, including a state of non-judgment and attentional focus directed to the present (Greeson, 2009). The facet of mindfulness most emphasized by coaches and 
EXPERTISE AND PERFORMANCE PSYCHOLOGY IN CIRCUS

performers was the need to be present "in the here and now". According to one performer:

"You need to be generous with the public. As long as you give all the energy you have, you will be fine". Circus is a continuous dialogue with the audience and the viewers need to feel that the performer is "in the moment". Indeed, the ability to remain focused while allocating the proper energy level to the task at hand has long been associated with optimal performance experiences in movement sciences and sport psychology (Hanin, 2007). Similar to professional athletes, circus performers need to cope with general and discipline-specific pressures to increase their likelihood of performing at peak level.

\section{General and discipline-specific performance pressures}

Experts are those who consistently perform at a high level and are able to overcome bio-psycho-social pressures (Ericsson, 2007; Filho \& Tenenbaum, 2015). During my time at NCS and CDS, I identified general and discipline-specific performance issues that can be addressed by applied professionals interested in working with circus performers.

\section{General performance pressures}

The actual or perceived pressure from the public influences the performance of all acro-artists. In this regard, research in sport psychology suggests that the presence of an audience may facilitate or debilitate performance depending on numerous factors (Strauss, 2002). Generally speaking, the presence of an audience facilitates the performance of an overlearned motor task. In fact, athletes engage in extensive practice to increase their selfefficacy to perform in front of an audience (Feltz et al., 2008). It is also perhaps for this reason that performers at NCS and CDS only perform well-mastered skills during shows. For instance, a juggler who is able to simultaneously juggle with nine balls/objects will likely juggle with only seven balls/objects during a show, taking into account the added pressure or stress associated with a live performance. Furthermore, an acrobat able to perform a triple twist (i.e., 1080 degree rotation in the air) will likely perform a double twist during a show. 
EXPERTISE AND PERFORMANCE PSYCHOLOGY IN CIRCUS

Noteworthy, all performers practice at an extremely high level and constantly push the limits of their physical and mental boundaries, in agreement with the notion of deliberate practice (see Ericsson, 2007). However, they will only showcase their overlearned skills in order to diminish the likelihood of choking in front of an audience.

The audience at circus shows tends to be supportive of the performers. In professional sports, the audience is often hostile towards away teams and poorly performing players (Jamieson, 2010). In contrast, the audience at a circus show wants the performers to feel comfortable in order to perform well and deliver an entertaining show. According to the performers, positive vibes from the audience facilitate performance, consistent with research on social facilitation (for a review see Strauss, 2002). Although a supportive audience is usually perceived as advantageous to performance, several performers noted that they strive to maintain a task-relevant focus, rather than diverting attention to the audience, in order to prevent mistakes in their routines.

\section{Discipline-specific performance pressures}

Different circus disciplines have unique idiosyncratic performance stressors that were identified by the performers. Next, I detail some of these pressures while highlighting how mental skills training can be used to cope with such stressors. These discipline-specific performance issues, along with suggested mental training approaches and techniques, are summarized in Figure 2.

Aerial actors: Solo trapeze and tight rope. All of the performers that I spoke with indicated "Fear of Injury" as the major performance stressor in aerial acts. Although fear (generally conceived) can be harmful to performance, there is evidence that this primal emotion serves an important self-protective function (Lang, 2010). In particular, during dangerous situations, such as in the case of aerial acts, fear may direct attentional focus and decision-making to task-relevant cues. Noteworthy, all performers at NCS and CDS were 
EXPERTISE AND PERFORMANCE PSYCHOLOGY IN CIRCUS

aware of action control strategies to deal with the potentially paralyzing effects of fear. They

hinted, albeit in non-technical terms, that the solution to overcoming fear is attentional control training and pre-performance routines. Circus acts are inherently dangerous and performers only practice and perform when confident in their ability to stay focused and block out distractors (e.g., audience noise; internal thoughts). Furthermore, all of the aerial actors I spoke with engaged in pre-performance routines to ensure that environmental factors (e.g., lighting, temperature) would not interfere with their ability to focus during dangerous acts.

Clowns. Several clowns mentioned "Pressure from the Audience" as a major stressor. In fact, externally regulated high-performance expectations have been linked to social anxiety and self-presentation concerns (Leary \& Jongman-Sereno, 2010). As one clown pointed out: "You are alone on stage and you must be funny all the time." Similarly, another clown highlighted that: "Everything revolves around you...Y You have to change clothes quickly (between acts) and be back out there for the audience." A cognitive-behavioural approach centred on attentional control strategies, such as directing the attention to controllable "core components of action" associated with functional performance states (see Bortoli, Bertollo, Hanin, \& Robazza, 2012), could be a useful performance optimization strategy for clowns.

Contortionists. I conversed with two contortionists who both described the physical pain inherent to their discipline. "Pain Control", in their view, is the most challenging element of their performance. To deal with the pain, one contortionist mentioned the need "to train to acquire muscle endurance". Performance simulation training, which allows for the feeling of skill mastery that is the basis of self-efficacy (Bandura, 1997), may help contortionists' prepare their mind and body for performance, especially for long acts.

Furthermore, relaxation and biofeedback training are important techniques to ensure a healthy stress-recovery balance, particularly with respect to general well-being and reduction of 
EXPERTISE AND PERFORMANCE PSYCHOLOGY IN CIRCUS

somatic complaints (Kellmann, 2002). In this regard, there is evidence that relaxation and biofeedback training are among the most effective techniques to cope with pain (Schwartz \& Schwartz, 2003; Willmarth, Davis, \& Fitzgerald, 2014).

\section{Dual Acts: Dual-trapeze and hand-to-hand. For trapezists and hand-to-hand} performers (i.e., "catchers" and "flyers"; see Albrecht, 2006) “Group Dynamics” is a critical issue standing between poor and optimal performance. In a focus group with dual act acroartists, a general consensus evolved that the process of acquiring mutual trust is long and dynamic. The artists discussed how intensive training and open communication can improve performance in high-risk dyadic acts. Both theoretical and empirical evidence indicates that it takes time to develop high-performing teams and that task-specific training along with team building and communication exercises are paramount in developing team processes, such as cohesion and team coordination (Filho, Tenenbaum, \& Yang, 2015).

Jugglers. The jugglers disclosed during our conservations their "Fear of Failure". Performance errors are highly identifiable in juggling acts. One of the jugglers pointed out that "I am scared to drop it [balls or clubs]... Because if you drop it, everybody can see you made a mistake". A mindful performance enhancement approach (see Kaufman, Glass, \& Arnkoff, 2009) emphasizes staying in the present and refraining from judgmental thinking. This approach could help jugglers to (a) stay focused in the present (rather than in the past or future), thus diminishing the likelihood of error; and (b) reduce the likelihood of panicking following a mistake. Mindfulness acceptance techniques allow athletes to "embrace" failure without being overly critical or judgmental, as such thinking may lead to choking (see the reinvestment hypothesis; Masters \& Maxwell, 2008).

Jugglers also discussed the extremely challenging nature of practices and noted that quitting the circus has crossed their minds at times. This notion of "High-Risk of Overtraining" is explained by the extensive deliberate practice requirement of the discipline. 
EXPERTISE AND PERFORMANCE PSYCHOLOGY IN CIRCUS

According to one of the jugglers "It [juggling] is very lonely. You have to learn it and train hard by yourself." Practitioners working with jugglers should ensure appropriate stressrecovery balance by educating jugglers about the importance of passive (e.g., sleep and resting), active (e.g., hiking and physical activity), and pro-active (e.g., travelling) recovery activities (see Kellmann, 2002).

\section{Summary and future outlook}

My purpose in writing this paper was to share my experience at NCS and CDS from a performance enhancement perspective. The development of expert acro-artists requires learning the rules of the circus domain, transferring motor skills to the circus environment, and developing an artistic identity and a mindful mind-set. Furthermore, circus performers have their own discipline-specific performance demands. Aerial acro-artists, clowns, contortionists, hand-to-hand acts, and jugglers can all benefit from mental skills training addressing their unique needs. In this context, practitioners should be aware that mental training should not only be domain and discipline specific but also person-centred and idiosyncratic in nature.

My experience at NCS and CDS illustrated that various sport psychology techniques are applicable to the circus domain. To this extent, current conceptual frameworks of mental toughness might be useful to orient intervention programs in the circus arts. On one hand, mental toughness training programs should be delivered from a global stance, in the sense that the programs should cover the mental skills considered to be key to the development of expert performance across domains of human activity. On the other hand, mental toughness programs should be discipline-specific, as they should consider the unique requirements of a given sport or, as in the present case, the idiosyncrasies of each circus discipline (see

Gucciardi \& Gordon, 2007; Jones, 2002). 
EXPERTISE AND PERFORMANCE PSYCHOLOGY IN CIRCUS

Coalescing the ideas presented herein with current models of mental skills training may help professionals working with performance artists in general, and circus performance in particular. Notwithstanding, further applied research is needed to advance guidelines related to performance psychology in circus. For instance, a large-scale grounded-theory project could help to identify the performance challenges and mental skill techniques most effective for the circus environment.

For a unique perspective about expertise development and performance psychology in circus, I have asked two senior circus professionals (with teaching, coaching, casting, and directing experience) to independently reply to this commentary (below). Additionally, I would like to invite practitioners and researchers at large to further study the process of expertise development and use of mental skills training in circus.

\section{Reply from Patrice Aubertin: Director of Research and Teacher Training at the}

\section{National Circus School}

I thank the author for the enlightening article. The experiential approach used to capture some of the elements pertaining to performance in the circus arts domain is quite instructive. There are two particular aspects of the paper that stimulated my thinking. The first aspect pertains to the "acrobatic-artistics" construct coined as "acro-artist" in the article. Although I understand the descriptive nature of the term and its utility in helping us describe what circus artists do, I wonder if this dualistic approach should not be replaced by an “identity driven construct”. My point being that, although circus artists are using an acroartistic approach to express their art, I doubt they consider themselves as "acro-artists", but rather as "circus artists".

Secondly, the paper talks about the mechanisms participants are using to cope with audience effects. This is interesting because there is a strong belief amongst circus artists that they perform "for an audience" as opposed to performing "in front of" an audience as a mean 
EXPERTISE AND PERFORMANCE PSYCHOLOGY IN CIRCUS

to create a strong communication, or communion, with the audience. The paper points, however, at coping mechanisms that aim at promoting task-relevant focus, hence diverting attention from the audience to prevent mistakes during performance. It would be interesting to see if this strategy is counterproductive in creating a connection with the audience. Of equal interest, could we use performance psychology constructs that would alleviate this disconnection while maintaining a mistake-free performance?

\section{Reply from Bernard Petiot: Vice President of Casting and Performance at Cirque du Soleil}

This article is very interesting and instructive in many ways. The author has been able to capture the core pillars of "stage performance" demands within the domain of circus.

Learning about the rules of the domain, stage presence, balancing the needed attention of the skill execution while being emotionally engaged and connected with the audience, as well as coping with the pressure of delivering an excellent performance, are all fundamentals to understand the psychology of stage performance. The authors' references to various performance psychology concepts available in the literature are very useful to better understand the nature of the demand beyond the skills itself. This understanding is important to set up pertinent and useful intervention programs to support the artists. The disciplinespecific performance pressure should be further developed to better understand the underlying psychological demand and the variability from artist to artist. While performance psychology is well recognized as a key contributor to success in high level sports, in the circus world performance psychology has not yet reached a pervasive level. The focus is still on skill acquisition while leaving the underlying psychological skills and ability to "intuition". That being said, more is to know about the psychological strategies and techniques that unique circus artists have to develop in order to become expert performers. 
EXPERTISE AND PERFORMANCE PSYCHOLOGY IN CIRCUS

References

Albrecht, E. (2006). The contemporary circus: Art of the spectacular. Lanham, MD: Scarecrow Press.

Bandura, A. (1997). Self-efficacy: The exercise of control. New York, NY: W. H. Freeman.

Bortoli, L., Bertollo, M., Hanin, Y., \& Robazza, C. (2012). Striving for excellence: A multiaction plan intervention model for shooters. Psychology of Sport and Exercise, 13, 693-701. doi:10.1016/j.psychsport.2012.04.006

Braun, V., \& Clarke, V. (2006). Using thematic analysis in psychology. Qualitative Research in Psychology, 3, 77-101. doi:10.1191/1478088706qp063oa

Csikszentmihalyi, M. (1996). Creativity: Flow and the psychology of discovery and invention. New York, NY: Harper Perennial.

Ericsson, K. A. (2007). Deliberate practice and the modifiability of body and mind: Toward a science of the structure and acquisition of expert and elite performance. International Journal of Sport Psychology, 38, 4-34.

Feltz, D., Short, S., \& Sullivan, P. (2008). Self-efficacy in sport. Champaign, IL: Human Kinetics.

Filho, E., Gershgoren, L., Basevitch, I., \& Tenenbaum, G. (2014). Profile of high-performing college soccer teams: An exploratory multi-level analysis. Psychology of Sport and Exercise, 15, 559-568. doi:10.1016/j.psychsport.2014.05.008

Filho, E., \& Tenenbaum, G. (2012). Team mental models in sports: An overview. In R. Schinke (Ed.), Athletic insight's writings in sport psychology. Hauppauge, NY: Nova Science Publishers, Inc.

Filho, E., \& Tenenbaum, G. (2015). Sports psychology. Oxford bibliographies. Oxford, United Kingdom: Oxford University Press. doi:10.1093/OBO/9780199828340-0175 
EXPERTISE AND PERFORMANCE PSYCHOLOGY IN CIRCUS

Filho, E., Tenenbaum, G., \& Yang, Y. (2015). Cohesion, team mental models, and collective efficacy: towards an integrated framework of team dynamics in sport. Journal of Sports Sciences, 33, 641-653. doi:10.1080/02640414.2014.957714

Greeson, J. M. (2009). Mindfulness research update: 2008. Complementary Health Practice Review, 14, 10-18. doi:10.1177/1533210108329862

Gucciardi, D. F. \& Gordon, S. (2007) (Eds.). Mental toughness in sport: Developments in theory and research. Abingdon, Oxon: Routledge.

Hanin, Y. L. (2007). Emotions in sport: Current issues and perspectives. In G. T. Tenenbaum \& R. C. Eklund (Eds.) Handbook of sport psychology (3rd ed., pp. 31-58). New York, NY: Wiley.

Hollingshead, A. B., \& Brandon, D. P. (2004). Transactive memory systems in organizations: Matching tasks, expertise and people. Organization Science, 15, 633-644.

Jamieson, J. P. (2010). The home field advantage in athletics: A meta-analysis. Journal of Applied Social Psychology, 40, 1819-1848. doi:10.1111/j.1559-1816.2010.00641.x

Jones, G. (2002). What is this thing called mental toughness? An investigation of elite sport performers. Journal of Applied Sport Psychology, 14, 205-218.

Kaufman, K. A., Glass, C. R., \& Arnkoff, D. B. (2009). Evaluation of mindful sport performance enhancement (MSPE): A new approach to promote flow in athletes. Journal of Clinical Sport Psychology, 3, 334-356.

Kellmann, M. (2002). Underrecovery and overtraining: Different concepts - similar impact? In M. Kellmann (Ed.), Enhancing recovery: Preventing underperformance in athletes (pp. 3-24). Champaign, IL: Human Kinetics

Kellmann, M. (2010). Preventing overtraining in athletes in high intensity sports and stress/recovery monitoring. Scandinavian Journal of Medicine \& Science in Sports, 20, 95-102. doi:10.1111/j.1600-0838.2010.01192.x 
EXPERTISE AND PERFORMANCE PSYCHOLOGY IN CIRCUS

389

390

391

392

393

394

395

396

397

398

399

400

401

402

403

404

405

406

407

408

409

410

411

Lang, P. J. (2010). Emotion and motivation: Toward consensus definitions and a common research purpose. Emotion Review, 2, 229-233. doi:10.1177/1754073910361984

Leary, M. R., \& Jongman-Sereno, K. P. (2010). Social anxiety as an early warning system: A refinement and extension of the self-presentation theory of social anxiety. In S. G. Hofmann \& P. M. DiBartolo (Eds.), Social anxiety: Clinical, development, and social perspectives. Waltham, MA: Academic Press.

Leroux, L. P. (2014). Contemporary circus research in Quebec: Building and negotiating and emerging interdisciplinary field. Theatre Research in Canada/Recherches théâtrales au Canada, 35(2).

Masters, R., \& Maxwell, J. (2008). The theory of reinvestment. International Review of Sport and Exercise Psychology, 1, 160-183. doi:10.1080/17509840802287218

Ménard, J. F., \& Hallé, M. (2014). Circus also needs performance psychology: Facts and realities of consulting at Cirque du Soleil. In J. G. Cremades \& L. S. Tashman (Eds.), Becoming a sport, exercise, and performance psychology professional: A global perspective. New York, NY: Psychology Press.

Mohammed, S., Ferzandi, L., \& Hamilton, K. (2010). Metaphor no more: A 15-year review of the team mental model construct. Journal of Management, 36, 876-910. doi:10.1177/0149206309356804

Nordin-Bates, S. (2012). Performance psychology in the performing arts. In S. Murphy (Ed.), The Oxford handbook of sport and performance psychology (pp. 81-114). New York, NY: Oxford University Press.

Patton, M. Q. (2002). Qualitative research and evaluation methods (3rd ed.). Thousand Oaks, CA: Sage Publications. 
EXPERTISE AND PERFORMANCE PSYCHOLOGY IN CIRCUS

412

413

414

415

416

417

418

419

420

421

422

423

424

425

426

427

428

429

430

431

Rafaeli-Mor, E., \& Steinberg, J. (2002). Self-complexity and well-being: A review and research synthesis. Personality and Social Psychology Review, 6, 31-58. doi:10.1207/S15327957PSPR0601_2

Schinke, R. J., Gauthier, A. P., Dubuc, N. G., \& Crowder, T. (2007). Understanding athlete adaptation in the national hockey league through an archival data source. The Sport Psychologist, 21, 277-287.

Schwartz, N. M., \& Schwartz, M. S. (2003). Definitions of biofeedback and applied psychophysiology. In M. Schwartz \& F. Andrasik (Eds.), Biofeedback: A practitioner's guide (3rd ed., pp. 27-39). New York, NY: Guilford Press.

Strauss, B. (2002). Social facilitation in motor tasks: A review of research and theory. Psychology of Sport and Exercise, 3, 237-256. doi:10.1016/S1469-0292(01)00019-X

Tenenbaum, G., Basevitch, I., Gershgoren, L., \& Filho, E. (2013). Emotions-decision-making in sport: Theoretical conceptualization and experimental evidence. International Journal of Sport and Exercise Psychology, 11, 151-168. doi:10.1080/161219X.2013.773687

Wang, J., \& Chen, S. (2014). Transfer of learning: The key principle of motor skill training implementation. Applied Motor Learning in Physical Education and Sports. Morgantown, WV: FiT Publishing.

Willmarth, E., Davis, F., \& Fitzgerald, K. (2014). Biofeedback and integrative medicine in the pain clinic setting. Biofeedback, 42, 111-114. doi:10.5298/1081-5937-42.03.10 